\title{
SCREENING FOR GYNAECOLOGIC CANCERS IN GENETICALLY PREDISPOSED WOMEN
}

\section{Professor Greta Dreyer}

$\mathrm{MBChB}$ (Pret)

MMed (O et G) (Pret)

$\operatorname{MCOG}(\mathrm{SA})$

$\mathrm{PhD}$

Gynaecologic Oncology Unit

Department of Obstetrics and Gynaecology

University of Pretoria

South Africa

\section{Corresponding author:}

Tel +27123543900

Fax $\quad+27123250302$

E-mail_gretadreyer@mweb.co.za

Address $\quad 183$ Charles Street

Brooklyn

0181

Total words: Abstract 146

Body total: $\quad 6400$

References: 2980 


\section{ABSTRACT}

Hereditary breast and ovarian cancer (HBOC) syndrome and hereditary nonpolyposis colon cancer (HNPCC) syndrome are the two most important syndromes responsible for inherited cancers in gynaecology. Genetic testing is available for both these syndromes. BRCA testing is affordable and easy in patients with ancestry where the mutation patterns are known, other population groups need full gene screening. HNPCC can now be diagnosed more frequently with the use of immunohistochemistry.

Ovarian cancer risk is high in HBOC syndromes and advanced screening techniques should be used when preventive surgery is not an option. Early detection techniques offer less protection than prophylactic removal, but enable the patient to retain her reproductive organs. Oophorectomy has the advantage of reducing breast cancer risk.

In colorectal cancer syndromes the risk for endometrial and ovarian cancer is much elevated. These risks should be recognised and addressed as these diseases are easy to prevent.

Key words: inherited susceptibility, cancer screening, BRCA, HNPCC

\section{INTRODUCTION}

Female lower genital tract cancers are strongly linked to infection with carcinogenic papilloma viruses. Cancers of the upper genital tract are linked to different risk factors, of which family history of related cancers or genetic risk is the strongest independent predictor. Between 5 and $15 \%$ of ovarian and uterine cancer cases are directly attributable to inherited mutations in high penetrance cancer predisposition genes [1].

If genetic risk factors are recognized and correctly managed, the chance of the individual to develop and die from cancer should be lowered. The identification of genetic risk depends strongly on obtaining and correctly interpreting the family history. In addition to an excess of cancer cases in the family history, certain disease phenotypes indicate that malignancy may have developed due to an inherited disorder. Examples include bilateral or triple negative breast cancer, synchronous uterine and ovarian cancer and bilateral breast cancer. 
Risk reduction must include both strategies to improve cancer survival by early detection (generally this equal intensified screening and the down-staging of cancer) and strategies to prevent the development of cancer (prophylactic medical and surgical measures or primary prevention) [2,3]. It is very uncommon to diagnose cancer precursor disease in the upper tract, therefore secondary prevention usually does not apply.

It is not possible to discuss screening for women with inherited cancer predisposition without also addressing the other risk reducing strategies [4]. While the focus will be on screening for gynaecologic cancers in this review, other risk reducing measures will also be discussed briefly.

Breast cancer is an important part of cancer syndromes related to gynaecologic cancer. Breast cancer diagnosis in the family or patient as a significant marker of genetic risk for gynaecologic cancer will be addressed. Reduction of breast cancer risk is an important aim for these patients and chapter 12 is dedicated to breast screening.

\section{IDENTIFICATION OF POSSIBLE GENETIC PREDISPOSITION}

The diagnosis and management of families and individuals with cancer predisposition syndromes are complicated. Detailed knowledge and understanding of clinical genetics, gynaecology and psychology as well as experience in counselling, cancer risk evaluation, prevention and screening techniques are all essential. Management by a multi-disciplinary team skilled in all these mentioned aspects is highly recommended [4].

On the other hand it is acknowledged that these families and patients are often recognised and treated appropriately at generalist level by well-informed health care workers. Specialist genetic counselling services are not widely available in all parts of the world and when available it is often limited to large centres. Genetic testing is unaffordable for most people in the world. All gynaecologists should have at least basic knowledge of the related cancer syndromes and of cancer risk management strategies. Diagnostic options should include genetic testing as well as probability diagnosis and risk assessment.

\subsection{CANCER SYNDROMES}

Cancer is by nature a disease of accumulated genetic abnormality in the cells. The genes most often mutated in cancer cells are those responsible for the 
regulation of cell growth and division. Some of these genes are also commonly involved in the inherited cancer syndromes, and then mutated in all germ line cells. Many scarce genetic disorders may increase cancer risk, but the two important syndromes responsible for the majority of inherited cancers in the gynaecologic organs are:

- Hereditary breast and ovarian cancer (HBOC) syndrome, including sitespecific ovarian cancer syndrome (SSOC); and

- Hereditary non-polyposis colon cancer (HNPCC) syndrome, also named Lynch syndrome (LS).

\subsubsection{Hereditary breast and ovarian cancer syndrome}

Genetic mutations in the BRCA1 (chromosome 17p) and BRCA2 (chromosome 13q) genes are found in the large majority of families (around $85 \%$ depending on the criteria used) with a pattern of inherited cancer of the breast and/or ovaries [5,6]. Both these high-penetrance genes encode for tumour suppressor proteins and more than 1200 different mutations have been described in each large gene $[5,6,7,8]$. Mutations will inactivate the protein product partially, leading to increased susceptibility to endogenous and exogenous carcinogens [7].

Mutation patterns are strongly population specific and inheritance is autosomal dominant with varying penetrance of disease. The prevalence of BRCA mutations differs per population group and many groups display a founder effect, enabling cheaper meaningful gene testing $[9,10]$.

The BRCA genes do not explain all families with HBOC or SSOC syndrome and it seems more than likely that other genes, hitherto unidentified, are also important. [11] Specifically families displaying an excess of breast cancer only, will often not harbour a BRCA mutation [10]. The other involved genetic factors may be recessive (as suggested by the excess in sibling compared to offspring risk), or may be dominant but with a smaller penetrance than the BRCA genes [12].

\subsubsection{Hereditary non-polyposis colon cancer syndrome}

This syndrome, originally named Lynch syndrome, is caused by autosomal dominantly inherited germline mutation in one of the genes involved in the 
DNA mismatch repair (MMR) pathway [13]. The three most common genes involved are MLH1, MSH2 and MSH6 and mutations predispose mainly to gastro-intestinal (colorectal, stomach, small bowel, pancreas), uro-gynaecologic (renal, endometrial, ovarian) and brain cancer [13].

Importantly, in women from these families, the most common cancer is endometrial cancer (usually reported as "uterine") followed by colorectal cancer $[14,15,16,17]$. Mutations in these genes also explain about $10 \%$ of families with a pattern of inherited ovarian cancer $[18,19]$

\subsection{MARKERS OF GENETIC PREDISPOSITION}

\subsubsection{FAMILY HISTORY}

Basic questions about the family history of related cancer will detect the majority of families who harbour a mutation in one of the high prevalence cancer predisposition genes. Family history remains the backbone of risk calculation to determine the appropriateness of gene testing and estimate the probability of an inherited susceptibility. The total incidence of related cancers are taken into account and the occurrence of more unusual disease phenotypes will add more to the calculated risk of genetic predisposition.

In this way, the diagnosis of ovarian cancer, being a less common neoplasm, is a stronger predictor of mutation in the family than breast cancer [20]. Breast cancer diagnosed before the age of 40 years, in multiple family members or bilaterally is also more predictive of HBOC syndrome [11].

Male breast cancer is another important marker for HBOC families. The chance for BRCA2 mutation in an unselected male breast cancer patient (without a family history) is estimated between 5 and $20 \%$ and BRCA 1 may also cause the disease [21,22]._Any male breast cancer patient with a family history of breast and/ or ovarian cancer has a risk for BRCA mutation of more than $50 \%$. It is in the interest of family members to refer all male breast cancer patients for genetic counselling and testing where available and BRCA2 should be the first gene to test [23].

The important diagnostic markers of HBOC families are listed in Table I. 
Table I. Markers of families with HBOC syndrome

The following in the family history:

- Multiple cases of breast and / or ovarian cancer

- Early or pre-menopausal diagnosis of breast cancer

- Bilateral breast cancer

- Any single individual with both breast and ovarian cancer

- Male breast cancer

- Gland-related cancers (gastric, pancreatic, colon, thyroid)

- Ethnicity with a higher genetic mutation frequency (includes Icelandic, Ashkenazi Jewish, Swedish, Hungarian, French Canadian)

Lynch syndrome is greatly underdiagnosed, as it is difficult to suspect on family history alone and genetic testing is not widely available. The Amsterdam criteria were devised to identify families at risk to have hereditary nonpolyposis colorectal carcinoma [16]. These criteria required colorectal or associated cancers in three first-degree relatives, in two successive generations and at least once diagnosed under the age of 50 years [16]. It is now known that if these "strict" criteria are used as sole indication for testing, the majority of families will go undetected.

\subsubsection{DISEASE HISTORY}

Often inherited cancer susceptibility is only suspected at the time of cancer diagnosis or shortly thereafter. For the patient and clinicians involved in this complex situation the double diagnosis is difficult to deal with and the clinical implications not always fully explored. Therapeutic and prophylactic measures can have survival benefit for these patients and the diagnosis of hereditary cancer predisposition often has great predictive value for family members.

The familial pattern of disease can become apparent only after another new cancer diagnosis is made, but also certain disease patterns or "phenotypes" are 
associated with a much higher risk of inherited genetic risk [24]. These unusual phenotypes indicate exploration of genetic risk even in the absence of a strong family history.

\section{Hereditary breast and ovarian cancer}

The risk for BRCA mutation is between 7 and $18 \%$ in unselected ovarian cancer patients (without a family history) and about $14 \%$ of all cases are attributed to BRCA mutations in the United States [20]. Some authorities now recommend BRCA mutation testing for all women diagnosed with ovarian cancer [25,20]. Mutations are even more common among young patients and those with a family history. Referral for genetic counseling and testing should preferably be discussed early in the disease process in view of the poor prognosis of the disease and presents an effective way to diagnose inheritance and to detect healthy carriers (Table II) $[1,20]$.

Table II. Markers of individuals with HBOC syndrome

The following in the person's medical history:

- Diagnosed with both breast and ovarian cancer

- Diagnosed with ovarian cancer and has a close relative with ovarian cancer or early-onset breast cancer

- Ashkenazi Jewish origin and diagnosed with either ovarian or early-onset breast cancer

- Bilateral breast cancer, one before age 45 years

- A male patient with breast cancer

- Diagnosed with "triple negative, basal-like" breast cancer phenotype

Certain breast cancer phenotypes can also be used to suspect and diagnose BRCA mutations. Mutations are more common among women with early onset breast cancer, triple negative cancer and bilateral breast cancer [26]. The value of detecting BRCA mutation in a woman with newly diagnosed breast cancer, 
include the opportunity to discuss and offer more aggressive primary surgical treatment, simultaneous prophylactic contralateral breast surgery (and reconstruction), extra targeted chemo-therapy options (PARB-B) and early prophylactic oophorectomy as ablative therapy and ovarian cancer prevention [27].

\section{Hereditary non-polyposis colon cancer}

The so-called "strict Amsterdam criteria" (discussed above) may be too strict to diagnose the majority of families with a mutation in the mismatch repair genes. Due to this low sensitivity, testing is now recommended for a larger group of patients, including those identified on tumour or disease history $[28,29]$.

The Bethesda guidelines (published in 1996 and updated in 2002) outlined patient population groups that qualify for gene testing [29]. The guidelines recommend testing for the genes associated with HNPCC in women with endometrial cancer before the age of 45 years (12 to $25 \%$ of these cancers will be attributable to Lynch syndrome [30,31] and with synchronous endometrial and ovarian cancer. The age cutoff should be higher in endometrial cancer patients with any family history of HNPCC associated cancer [32]. Primary endometrial or ovarian cancer after previous colorectal cancer should always be investigated or considered HNPCC cases if gene testing is not available.

Immunohistochemical staining for the three MMR proteins in the tumour material of suspected cases can be used as a screening test. Absent or poor staining can be followed by testing for micro-satellite instability or by genetic testing [33]. Alternatively these cases can be considered positive for Lynch syndrome [34] if promoter methylation of MLH1 is excluded. Using these selection criteria, Lynch syndrome will be detected in $12 \%$ to $14 \%$ of the targeted patients [34] and most families will not fulfill the Amsterdam criteria.

\section{GENETIC DIAGNOSIS}

The confirmation and accurate diagnosis of inherited susceptibility depend on the availability of reliable and affordable genetic tests. Genetic testing is generally considered indicated if the chance for finding a mutation is 'reasonable', typically quoted as more than $10 \%$. Scoring systems have been developed to estimate this chance, including the Manchester scoring system [19]. In a recent review of the various models and scoring systems available for these purposes they were found not to have a high discriminatory accuracy [7]. 
When genetic testing is unavailable, not affordable or declined, cancer risk evaluation solely on the basis of the family history is also possible and can be done using published tables. The individual's personal risk profile is also taken into account. The Claus model allows for an estimated lifetime breast cancer risk as high as $45 \%$, based on the assumption that the family has a mutation [27], while the Gail model takes the epidemiological risk factors into account as well [35].

\subsection{GENETIC COUNSELLING}

Genetic testing is only ethical and useful if combined with counselling and implementation of risk-management strategies. The aims of genetic counselling are listed in table III.

Table III. Aims of genetic counselling

\begin{tabular}{|l|}
\hline Risk assessment \\
- Empiric risk factors \\
Behavioural risk \\
- Decrease cancer risk \\
- Ensure early cancer detection \\
Psychological assessment \\
- Evaluation \\
- Support
\end{tabular}


Pre-requisites for genetic testing and the content of the counselling conversation were developed by clinical genetics specialists [27] and is summarised in Table IV.

TABLE IV. Counselling pre-requisites before genetic testing

\section{THE PATIENT TO BE TESTED SHOULD BE FULLY INFORMED ABOUT THE FOLLOWING ASPECTS:}

The condition

- The penetrance and clinical presentation of the condition

- Patterns of inheritance and implications for family members and children

- Alternative to genetic testing for risk estimation

- Risk for mutation based on family history and available information

The test

- Information on the specific test and laboratory

- Implications of possible positive and negative results

- Possibility of a non-informative result

- Technical accuracy of the test

- Costs involved in testing and counselling

The management of inherited risk

- Possibilities and limitations of surveillance and preventative options

- Risk of psychological distress and insurance discrimination

- Confidentiality issues 


\subsection{TYPE OF GENETIC TEST}

Genetic testing for germline mutations far outperforms any other risk estimate [36] and is usually done on a peripheral blood sample on DNA extracted from leucocyte nuclei. It is most useful and cost effective to begin testing in a family with an individual who was diagnosed with cancer. Once the mutation in the family is identified, further testing is easy and inexpensive, as it is limited to a single mutation. Predictive testing can then be offered to family members without a personal cancer history.

In certain population groups founder mutations are present. These groups are characterised by a small ancestral group and genetic mutations tend to occur more frequently. Analysis may be limited to the frequently occurring mutations, which is more cost effective. In individuals or populations where founder mutations are not known to occur, the only useful testing is full screening of all the suspected genes.

Immunohistochemistry offers indirect genetic testing (in tumour tissue) by targeting the protein product of the gene as discussed above.

\subsection{INTERPRETATION OF TEST RESULT}

Three types of genetic results can be received. Firstly, the patient can test positive for a genetic mutation, implying inherited cancer susceptibility. The risk to develop cancer is predicted according to the mutated gene as well as the family history. (Table V)

Secondly, the tested individual can test negative for the genetic mutation and therefore has only the normal population background risk (or lower than that) to develop the relevant cancer. This interpretation can only be made when the specific genetic mutation in the family is known.

Thirdly, the test can be uninformative. In these cases the genetic mutation responsible for the increased cancer risk in the family (or individual) is not found or known, and the requested genetic test is negative. The existence of a genetic mutation in the known or unknown cancer genes that were not included in the test cannot be excluded and inherited susceptibility remains a possibility. 
TABLE V: THE POSITION OF SCREENING IN THE MANAGEMENT OF INHERITED CANCER RISK

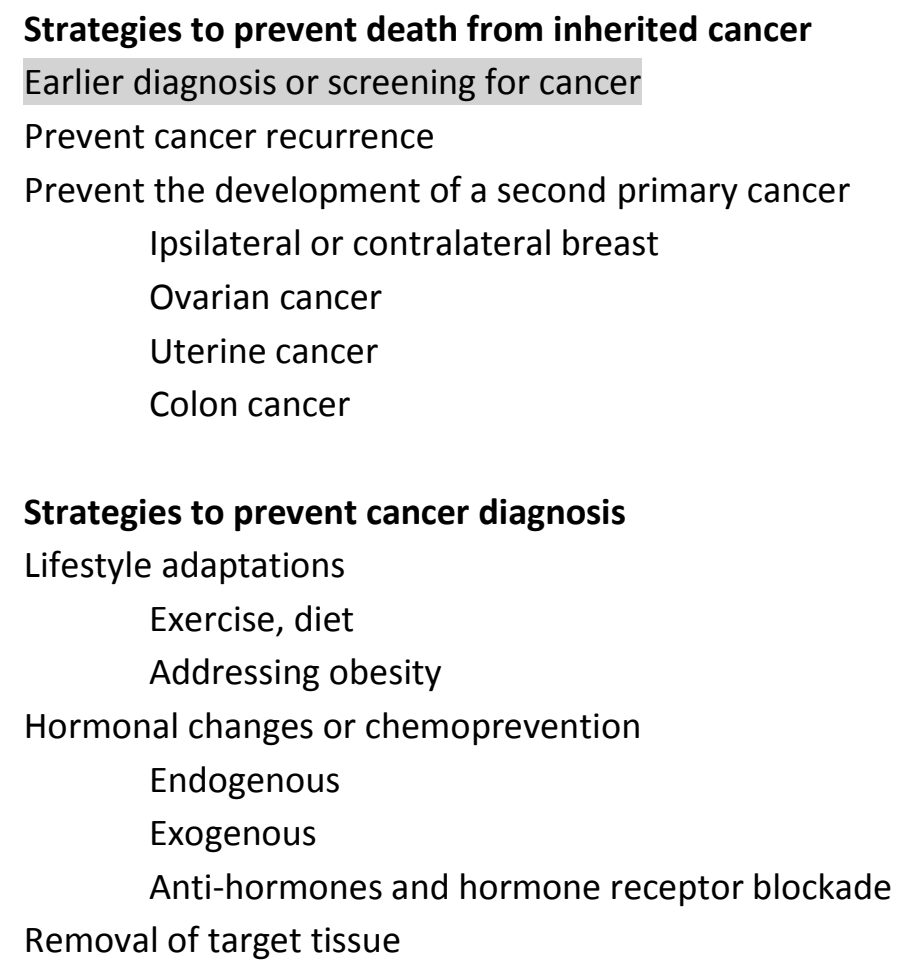

\section{GYNAECOLOGIC CANCER RISK}

Cancer risk estimates should be based on clinical history and all the available laboratory tests, including pathologic, genetic and epidemiologic risk factors. The risk category can then be used to suggest suitable management including screening and other risk reducing options.

A simple family history of ovarian cancer will increase the risk for the same disease three to four times, while endometrial cancer risk is increased by around two times according to existing literature [37,38]. On the other hand, testing positive for a cancer predisposing genetic mutation can confer extremely high risks for both ovarian cancer and endometrial cancer. It is important to estimate the individual risk as accurately as possible. 


\subsubsection{Hereditary breast and ovarian cancer syndromes}

Genetic mutation in the BRCA genes causes mainly breast, ovarian, fallopian tube and primary peritoneal cancer in women. The incidence of these diseases in mutation carriers is called penetrance. Different groups have reported widely varying penetrance in selected subgroups.

\section{Epithelial ovarian cancer}

Generally, the standardized incidence ratio for ovarian cancer in BRCA mutation positive women is around 10 if there is a first degree relative with the similar cancer and only slightly lower if not $[39,40,41]$. In carriers of BRCA mutation with ovarian cancer in the family history, the estimated lifetime risk for ovarian cancer is estimated between $30 \%$ (for BRCA2) and 44-63\% (for BRCA1) [42]. While earlier studies reported ovarian cancer mainly in BRCA1 families, some newer studies report similar penetrance and even similar mean ages for ovarian cancer in BRCA1 and BRCA2 families[23]. About 75\% of ovarian cancer occurring in BRCA mutation positive women have papillary serous histology.[43]

Women with ovaries and known to have a BRCA mutation has about a $20 \%$ chance to be diagnosed with ovarian cancer in the first nine years of follow up (depending on age at genetic diagnosis). The mean age at diagnosis is reported around 50 years, but ranges from 30 years to 73 years [44,45].

The risk to develop ovarian cancer within ten years after the diagnosis of breast cancer in women with a BRCA mutation was studied and reported as $12.7 \%$ and $6.7 \%$ respectively for BRCA1 and BRCA2 mutation carriers. In this study subsequent ovarian cancer was responsible for $25 \%$ of deaths of stage I breast cancer patients [46]. These two groups are obviously important target groups for risk reduction strategies.

At the time of prophylactic removal, ovarian pathology in mutation positive women is often suspected and described as pre-malignant or early malignant changes [47]. There is no consensus on the relevance of these findings which are currently not very reproducible. One large collaborative study detected six cases $(2.3 \%)$ of stage I invasive ovarian cancer among 259 BRCA mutated women undergoing prophylactic removal [44]. 


\section{Primary peritoneal cancer}

This disease almost invariably has papillary serous histology and more than $10 \%$ of cases are explained by germline BRCA mutations [48]. The malignancy is mostly but not completely prevented by prophylactic BSO $[49,44]$ and not amenable for screening.

\section{$\underline{\text { Fallopian tube cancer }}$}

Ovarian cancer is thought by many to often originate from the Fallopian tube epithelium and the incidence of primary fallopian tube cancer is not known. [50] In a large analysis of the cancer history of 700 BRCA1 European and North American families, fallopian tube cancer was reported 50 times more in BRCA1 mutation carriers than expected in the general population [51].

Several case reports have been published of patients with either BRCA1 or BRCA2 germline mutations developing tubal cancer [52,53]. In addition some molecular evidence links fallopian tube cancer convincingly to $\mathrm{HBOC}$ syndrome [54]. Any ovarian cancer risk reduction programme should therefore take the accompanying risk for fallopian tube cancer into account. Fallopian tube cancer is now considered part of the HBOC syndrome.

\section{$\underline{\text { Uterine cancer }}$}

Uterine body and endometrial cancer risk among women with BRCA mutations is difficult to estimate and most information is derived from family history offered by probands. In most studies the family members of mutation positive women reported a significantly higher incidence of uterine cancer than the probands of mutation negative women [10]. One large study based on family history of 11000 women, reports the risk for uterine cancer as 2.65 times the background population risk [51]

Although many case reports of uterine and uterine papillary serous carcinoma (UPSC) in mutation positive women have been published and women diagnosed with UPSC seem to have a family history suggestive of HBOC more often than expected [55], the risk in genetically predisposed women to develop these cancers seem relatively low. In addition BRCA mutations probably explain only a small proportion of uterine serous papillary cancers [56]. 


\section{Cervical cancer risk}

Various authors report an increased incidence of cervical cancer in BRCA mutation positive women. The relative risk is reported between 3 and 5 and described as a mild to moderately increased risk [57, 51]. Interaction or not with human papilloma virus is unknown.

\subsubsection{Hereditary non-polyposis colon cancer syndrome}

Inherited mutations in the MMR genes are responsible for this syndrome and are shown to be present in about $2 \%$ of all colorectal cancer cases. At the same time about $2 \%$ of all ovarian cases [58] and as high as $8 \%$ of young endometrial cancer cases are explained by such germline mutations.[30].

\section{Endometrial cancer}

While historically most families were identified due to a high prevalence of colorectal cancer, it is now known that female carriers of mutations in the causative genes have a higher risk for endometrial cancer than for gastrointestinal cancer $[59,60]$.

Similar to other clinical cancer syndromes, the risk for gynaecological cancer relates to the specific gene involved. Women with a mutated hMLH1 or hMSH2 gene have the highest lifetime risks for endometrial cancer, namely between 40 and $70 \%$ [59].

\section{$\underline{\text { Ovarian cancer }}$}

Genetic mutations in the MMR genes are frequently associated with either mucinous or endometrioid carcinoma [61,62] and also with synchronous endometrial and ovarian cancer.

Women with a mutated MSH2 gene also have the highest risk for ovarian cancer, possibly as high as $20 \%$ [59].

\section{Other gynaecologic cancer}

The risk for other gynaecologic cancers has not been studied extensively, but does not seem increased in the HNPCC syndrome. 


\subsubsection{Other cancer syndromes}

Not all familial clustering of endometrial or ovarian cancer is explained by the two syndromes discussed above. However these syndromes do explain almost all multi-case families, making other high-penetrance genes very unlikely [12].

Cowden syndrome is caused by germline mutation in the PTEN gene and is known to increase endometrial cancer risk. This risk has not been quantified sufficiently 63,64], but certainly warrants endometrial cancer screening.

\section{NON-GYNAECOLOGIC CANCER RISK}

\section{Hereditary breast and ovarian cancer syndrome}

Breast cancer remains the most common disease in female BRCA mutation carriers. The earlier development of breast cancer in affected individuals can also modify the risk of ovarian and other related cancers. A confirmed inherited BRCA mutation in a female is estimated to translate into a lifetime breast cancer risk of $70-90 \%$, higher if the family history is strong [62].

Some cancer incidence studies have found a significantly increased risk for a variety of other cancers, including stomach, pancreatic and melanoma [10]. Differences between the results suggest population and mutation specificity. Usually increased surveillance is not recommended.

\section{Hereditary non-polyposis colon cancer syndrome}

Mutations in the MMR genes are estimated to be responsible for up to $7 \%$ of all colon cancers [33]. The estimated lifetime colorectal cancer risk varies between 48\% (MLH2 mutation carriers) and 12\% (MSH6 mutation carriers).[59] and the mean age at diagnosis is 10 to 15 years earlier than in the general population.(61)

\section{Cowden syndrome}

This rare genetic disorder was recently demonstrated to dramatically increase colorectal cancer risk (even by 200 times) via the development of numerous initially benign polyps. Gastric cancer and thyroid cancer are also associated.[63, 64] 


\section{Li Fraumeni}

Li-Fraumeni syndrome is a rare disorder caused by germline mutation in the p53 or CHK2 genes that greatly increases the risk of developing several types of cancer, particularly in children and young adults. Soft tissue sarcomas, leukemia, brain and breast cancer are among the commonest cancers.

\section{SCREENING FOR EPITHELIAL OVARIAN AND RELATED CANCERS}

Ovarian cancer screening is currently usually based upon serum markers followed by imaging in those with abnormal values. Current strategies lack in specificity and have low positive predictive values $[65,66]$. This translates into many diagnostic surgeries for benign disorders. In addition ovarian cancer screening has not been demonstrated convincingly to improve outcomes when compared to detection due to symptoms. In many patients screen-detected cancer is already in stage III and screening failed to down-stage the disease [67].

To improve this performance, new sero-markers will be needed that has a longer lead-time [68]. Blood levels of current markers only increase less than a year before symptoms [31] Also, improved imaging must lead to less diagnostic operations for benign disease. One option is to add sonographic measurement of ovarian volume and use normal values adjusted for age [10]. Three-dimensional power Doppler evaluation may also aide diagnostic accuracy [69].

Screening for ovarian cancer cannot prevent disease at all, will not detect fallopian tube or peritoneal carcinoma early and for the reasons stated above, it is seriously doubted whether it will really improve survival significantly in women at very high risk for the disease.

\section{Hereditary breast and ovarian cancer syndrome}

In women with HBOC known or suspected to have a disease causing BRCA mutation, ovarian cancer screening offers a temporary alternative to surgical removal of the ovaries. It should be offered to those women who do not yet want prophylactic surgery or who are still in their child-bearing years.

Current guidelines suggest four to six monthly Ca125 testing, followed by transvaginal sonographic evaluation at least once per year or when the sero-marker is 
raised [70]. This regimen can be offered to all mutation positive women over 30 years of age, although it will not be cost-effective for women younger than 35 years. Women over the age of 40 years should be strongly motivated to undergo risk-reducing prophylactic salpingo-oophorectomy rather than continued ovarian screening [42].

BRCA positive breast cancer survivors should also be counselled and motivated for prophylactic surgery as the mortality due to ovarian cancer in these patients is high and preventable [71, 72].

\section{Hereditary non-polyposis colon cancer syndrome}

Women known to have a MSH2 mutation have an estimated lifetime risk of around $20 \%$ by age 70 years. These women should ideally undergo preventive oophorectomy as soon as is possible. When accurate ovarian cancer assessment is not possible, all family members should be regarded as positive.

\section{SCREENING FOR UTERINE CANCER}

Uterine endometrial cancer can be detected in early stages using either transvaginal ultrasound to evaluate the endometrium and / or using transcervical aspiration endometrial biopsy. When the endometrium is evaluated promptly in response to new symptoms, diagnosis is also usually made in early stages. For this reason it remains difficult to prove a survival benefit for screening to diagnose endometrial cancer in a curable stage.

Most data regarding endometrial screening relate to post-menopausal women deemed to be at high risk due to epidemiologic risk, symptoms, previous cancer history or tamoxifene use. These data suggest that transvaginal sonography is a useful test to triage for further endometrial evaluation. Post-menopausal women with a regular endometrium measuring less than $4 \mathrm{~mm}$ are extremely unlikely to have endometrial cancer.[73,74] Less data are available for younger women, but in these women a regular endometrium up to $6 \mathrm{~mm}$ thick, is regarded as normal [65].

\section{Hereditary non-polyposis colon cancer syndrome}

Screening for endometrial cancer is indicated in women from a family at risk for or known to have HNPCC syndrome. If screening is limited to patients who fulfil the strict criteria or who are from families with known mutations, the 
screening programme will be more cost-effective and more cancers will be diagnosed. On the other hand many families will be missed if stricter criteria are used.

Such screening can start around the age of 30 years, should be annual and should continue for life or until hysterectomy. At present, neither ultrasound screening nor endometrial aspiration biopsy has demonstrated an ideal sensitivity and interval cancers occurred between screening visits [75]. Most cancers were diagnosed in symptomatic patients.

A reasonable screening approach for women from HNPCC families, seem to be transvaginal ultrasound evaluation, followed by endometrial biopsy in all women with an abnormal ultrasound, symptoms (abnormal bleeding or discharge), abnormal tumour markers and all women above the age of 40 years.

It is unknown to what extent uterine cancer screening will improve survival of this disease which is hardly ever fatal and tends to be symptomatic in early stages. All these patients need ovarian cancer prevention or screening as well, and the combination may render more useful results. This is of special importance when the high incidence of concurrent or synchronous ovarian and uterine cancer is taken into account (More than 20\% of diagnosed ovarian cancer cases) [61]

It is now known that patients who underwent risk-reducing surgery developed much less endometrial cancers than those who did not. What is not known is how screening would compare with preventive surgery in terms of morbidity and survival. [76]

\section{Hereditary breast and ovarian cancer syndrome}

Screening for uterine cancer in patients with BRCA mutations are not widely recommended, because of the relatively low risk for uterine cancer. In women with a family history that includes uterine cancers, the risk may be sufficient to warrant either screening for or prevention of uterine cancers. Long term use of tamoxifen is another risk factor of importance [77]. Again pelvic ultrasound at the time of ovarian cancer surveillance is indicated, and this includes the evaluation of the endometrium in view of the RR of around 2.5 for endometrial cancer. 


\section{SCREENING FOR OTHER GYNAECOLOGIC CANCERS}

\subsection{Non-epithelial ovarian tumours}

Some uncommon genetic syndromes may cause an increased risk for nonepithelial cancer. The very uncommon Peutz-Jegher syndrome predispose to unusual variants of stromal tumours. Both benign and malignant teratomas have been described in families and can then occur bilaterally. Ovarian ultrasound screening will be indicated [71].

\subsection{Cervical cancer}

The guidelines for population based cervical cancer screening should be followed by women with BRCA gene mutation. It is not known whether HPVbased screening is a safe approach for these women and current guidelines will include cytological evaluation.

Women with Peutz-Jeghers syndrome should also undergo regular cervical cancer screening in view of the described increased incidence of adenocarcinoma.

\subsection{Uterine soft tissue tumours}

Uterine size, outline and morphology can be assessed accurately using transvaginal ultrasound. Uterine soft tissue tumours can be seen early and accurately using this modality in combination with Doppler flow studies. Women on prolonged treatment with tamoxifen to prevent breast cancer should probably also have such screening [78].

\section{SCREENING FOR NON-GYNAECOLOGIC CANCERS}

\subsection{BREAST CANCER}

Increased breast cancer surveillance aims to lower the mortality of breast cancer by lowering the size and stage of the tumor at the time of diagnosis. Extrapolating data from population screening programs, it is assumed that screening for breast cancer in high-risk individuals will also improve ultimate survival. Breast cancer screening is addressed in chapter 12. 


\subsection{COLON CANCER}

Mortality due to HNPCC syndrome can be reduced by yearly colonoscopy in individuals diagnosed with the genetic defect [61].

\section{PREVENTIVE OPTIONS FOR GENETICALLY PREDISPOSED WOMEN}

While cancer screening focuses on early detection and hope to reduce cancer mortality by down-staging, cancer prevention options hope to prevent the diagnosis of cancer and its treatment and disease related morbidity and mortality. Each of these risk-reducing strategies has an important place in the personalized management plan of women with inherited cancer predisposition. Screening cannot be discussed without the context of other risk-reducing options.

Medical and surgical gynaecologic cancer prevention options should be discussed with all patients, as well as the accuracy and place for screening options. The uptake of risk reduction advice varies widely and factors that influence behavior have been studied extensively and were reviewed recently [79]. Counseling and opinions of all encountered clinicians play important roles, as do genetic test results, parity, age, previous medical and family history.

\subsection{Ovarian and fallopian tube cancer}

\section{Medical prevention}

Oral contraceptives (OCs) reduce ovarian cancer risk moderately in the general population and probably also in BRCA positive women. Medical prevention is seldom prescribed due to the high uptake of risk-reducing surgery at age 40 years and the difficulty to draw conclusions regarding the influence of OCs on breast cancer risk [70].

\section{$\underline{\text { Surgical prevention }}$}

Removal of the complete fallopian tube and ovary with a segment of the ovarian vessels will reduce ovarian cancer risk by at least $90 \%$ [72,50]. The complete surgical specimens should be thoroughly sectioned and examined for early or in-situ cancer. Occult or clinical primary cancer in both the ovaries and tubes as well as breast cancer metastases are not uncommon in this patient 
population [76,47]. Peritoneal washings should be obtained and examined by cytology. It seems that previous reports overestimated the incidence of primary peritoneal carcinoma following preventative oophorectomy, possibly due to missed diagnosis of early or occult cancer at the time of surgery [48]. This surgery can be followed by hormone replacement in HBOC patients without apparent detrimental effect [80].

Gonadectomy for ovarian cancer prevention in HBOC patients can be performed any time before the diagnosis of ovarian cancer has been made, but is best planned for around the age of 40 years [80]. Earlier oophorectomy is advised for breast cancer risk reduction and should be considered around the age of 35 years [81].

Gonadectomy after the diagnosis of breast cancer will prevent subsequent primary ovarian cancer; help prevent second primary breast cancer as well as recurrence of disease $[82,83]$.

In patients from HNPCC families, the ideal age for oophorectomy is unknown but it is usually recommended at the same age as hysterectomy [84]. Generally few women will develop uterine or ovarian cancer before the age of 35 years, and most women will agree to preventive surgery around the age of 40 years.

\subsection{Uterine cancer}

\section{$\underline{\text { Medical prevention }}$}

High dose, long term and intra-uterine progestogen treatment are known to reduce endometrial cancer risk. In addition progestogens are known to reduce colon cancer risk and the intra-uterine progestogen containing IUS is not associated with an increase in breast cancer risk.

\section{$\underline{\text { Surgical prevention }}$}

Hysterectomy is highly effective to reduce endometrial cancer risk and is the risk reduction strategy of choice in women diagnosed with HNPCC who have finished child-bearing. On the other hand a survival benefit for this strategy above screening has not been demonstrated. 
Hystero-salpingo-oophorectomy should be offered to HNPCC women undergoing surgery for colon carcinoma. This will prevent ovarian metastasis as well as second primary gynaecologic malignancy.

Hysterectomy in HBOC syndrome should be discussed according to the individualized risk-benefit ratio [85].

\subsection{Breast cancer}

Preventing breast cancer will have a stronger impact on ultimate survival than screening alone, but the measures needed are also inherently more invasive and more radical.

\section{$\underline{\text { Medical prevention }}$}

Chemoprevention or hormonal prevention options include the use of tamoxifen and raloxifene prophylactic oophorectomy [81]. Worthwhile lifestyle adaptations include an increase in physical activity [86], low fat diet and management of obesity.

\section{Surgical prevention}

Mastectomy is the most effective way to prevent breast cancer. Options include mastectomy rather than breast conservation after diagnosis of breast disease [87], contra-lateral prophylactic mastectomy [62] and bilateral risk reducing mastectomy $[88,89]$. The uptake of risk reducing options is highly variable $[90,91]$ as it is with ovarian carcinoma [92]. All these options are offered with reconstruction.

\section{CONCLUSION}

Genetic evaluation, counselling and testing is an essential part of modern medicine. This can be used together with models to estimate risk using clinical parameters [93]. Once cancer risk is identified and also "quantified", risk management becomes important. Active cancer prevention is the most effective way to prevent morbidity and premature cancer related death in women known to have mutations in the genes causing HBOC and HNPPC syndromes. 
Many patients will postpone cancer prevention or will opt against preventive surgeries and will therefore request and / or need cancer screening. Cancer screening visits provide the ideal opportunity for on-going counselling and support. Screening should be intensive in patients at very high risk and any abnormal result must be followed up. Symptomatic patients need diagnostic tests rather than the routine screening approach.

Specialists who have an intimate knowledge and understanding of the field can best help their patients to make the correct decisions to protect themselves. Gynaecologists are uniquely positioned to help prevent deaths from hereditary cancer syndromes.

\section{Conflict of interest statement}

The author does not have any conflict of interest to declare

\section{PRACTISE POINTS}

- Family history is an extremely important tool to recognize possible inherited cancer risk

- Genetic tests should be used following comprehensive counseling to confirm inherited cancer risk

- Some cancer phenotypes are strongly suggestive of cancer predisposition due to a germline mutation

- Immunohistochemistry is an important tool to diagnose HNPCC families

- Screening for endometrial and ovarian cancer has an important but limited role in women at high risk

- Screening visits should be used to optimize cancer risk reduction and to plan the timing of possible preventative interventions 


\section{RESEARCH AGENDA}

\section{- Service delivery:}

Better distribution of the available tests and genetic counselling services

Better interaction between clinicians and counsellors

- Genetic testing:

Improved tests to accurately and affordably diagnose HNPCC

More affordable BRCA full gene screening tests

- Clinical and preclinical research:

Highly sensitive biochemical markers of early pre-neoplastic or neoplastic ovarian disease is needed

Biomarkers for endometrial neoplasia

\section{REFERENCES}

01 Easton D, Ford D, Bishop DT \& Breast Cancer Linkage Consortium. Breast and ovarian cancer incidence in BRCA1 mutation carriers. Am J Hum Genet 1995; 56: 265-271.

02 Domchek SM, Friebel TM, Singer CF, Evans G, Lynch HT, \& Isaacs C. Association of Risk-Reducing Surgery in BRCA1 or BRCA2 Mutation Carriers With Cancer Risk and Mortality. JAMA 2010; 304: 967-975.

03 Scheuer L, Kauff N, Robson M et al. Outcome of preventive surgery and screening for breast and ovarian cancer in BRCA mutation carriers. J Clin Oncol 2002; 20: 1260-1268.

04 Evans DG, Lalloo F, Ashcroft L et al. Uptake of risk-reducing surgery in unaffected women at high risk of breast and ovarian cancer is risk, age, and time dependent. Cancer Epidemiol Biomarkers Prev 2009; 18:2318-2324. 
05 Friedman LS, Ostermeyer EA, Szabo CI et al. Confirmation of BRCA1 by ananlysis of germline mutations linked to breast and ovarian carcinoma in ten families. Nature Genet 1994; 8: 399-404.

06 Wooster R, Bignell G, Lancaster J et al. Identification of the breast cancer susceptibility gene BRCA2. Nature 1995; 378: 789-792.

07 Ibrahim SS, Hafez EE, Hashishe MM. Presymptomatic breast cancer in Egypt: role of BRCA1 and BRCA2 tumour suppressor genes mutation detection. J Exper Clin Cancer Res 2010; 29:82-84.

08 Couch FJ, Sinilnikova O, Vierkant RA et al. Polymorphism and Breast Cancer Risk in BRCA1 and BRCA2 Mutation Carriers: A Consortium of Investigators of Modifiers of BRCA1/2 Study. Cancer Epidemiol Biomarkers Prev 2007; 16: 1416-1421.

09 Reeves MD, Yawitch TM, Van der Merwe NC, Van den Berg HJ, Dreyer G, Van Rensburg EJ. BRCA1 mutations in South African breast and/or ovarian cancer families: evidence of a novel founder mutation in Afrikaner families. Int J Cancer 2004; 110:677-682.

10 Schlebusch CM, Dreyer G, Sluiter MD, Yawitch TM, Van den Berg HJ, Van Rensburg EJ. Cancer prevalence in 129 breast-ovarian cancer families tested for BRCA1 and BRCA2 mutations. S Afr Med J 2010; 100: 113-117.

11 Moslehi R, Chu W, Karlan B, Fishman D, Risch H, Fields H. BRCA1 and BRCA2 analysis of 208 Ashkenazi Jewish women with ovarian cancer. Am J Hum Genet; 2010; 100: 113-117.

12 Antoniou AC, Spurdle AB, Sinilnikova OM, Healy S, Pooley KA \& Schmutzler RK. Common breast cancer-predisposition alleles are associated with breast cancer risk in BRCA1 and BRCA2 mutations carriers. Am J Hum Genet 2008; 82: 937-948.

13 Meyer LA, Broaddus RR, Lu KH. Endometrial cancer and Lynch syndrome: clinical and pathologic considerations. Cancer Control 2009; 16: 1422.

14 Grindedal EM, Blanco I, Stormorken A, Maehle L, Clark N \& Gonzalez S. High risk of endometrial cancer in colorectal cancer kindred is pathognomonic for MMR-mutation carriers. Familial Cancer 2009; 8: 145-151. 
15 Taylor N, Mutch DG. Gynecologic manifestations of hereditary nonpolyposis colorectal cancer. From inherited to sporadic disease. [Review]. Oncology 2006; 94: 85-94.

16 Vasen HF, Watson P, Mecklin JP et al. New clinical criteria for hereditary nonpolyposis colorectal cancer (HNPCC, Lynch syndrome) proposed by the International Collaborative Group on HNPCC. Gastroenterology 1999; 116: $1453-1456$.

17 Watson P, Lynch HT. Cancer risk in mismatch repair gene mutation carriers. Fam Cancer 2001; 1: 57-60.

18 Russo A, Calo V, Bruno L, Rizzo S, Bazan V, Di Fede G. Hereditary ovarian cancer. Crit Review Oncol-Hematol 2009; 69:28-44.

19 Evans DG, Lalloo F, Wallace A, Rahman N. Update on the Manchester Scoring System for BRCA1 and BRC2 testing. J Med Genet 2004; 41(7):474480 .

20 Kwon JS, Daniels MS, Sun CC, Lu KH. Preventing future cancers by testing women with ovarian cancer for BRCA mutations. J Clin Oncol 2010; 28:675-682.

21 Brenner RJ, Weltzel JN, Hansen N, Boasberg P. Screening-detected Breast Cancer in a Man with BRCA2 Mutation: Case Report. Radiol 2004; 230: 553-555.

22 Franks TS, Deffenbaugh AM, Reid JE et al. Clinical characteristics of individuals with germline mutations in BRCA1 and BRCA2: analysis of 10,000 individuals. J Clin Oncol 2002; 20:1480-1490.

23 Antoniou A, Pharoah PD \& Narod S. Average risks of breast and ovarian cancer associated with BRCA1 and BRCA2 mutations detected in case series unselected for family history: a combined analysis of 22 studies. Am J Hum Genet 2003; 72: 1117-130.

24 Miguel DH, Osorio A, Goding J, Selleiro S, Tosar A \& Perez-Segura P. Association between BRCA1 and BRCA2 mutations and cancer phenotype in Spanish breast/ovarian cancer families: Implications for genetic testing. Int $J$ Cancer 2002; 97: 466-471. 
25 Gulden C \& Olopade OL. Risk assessment and genetic testing for ovarian cancer. [Review]. Am J Roentgenol 2010; 194: 309-310.

26 Somer R, Farengo-Clark D, Patel A, Schwarting R, Grana G \& Rodier E. Risk, Epidemiology and Prevention- Familial Breast Cancer -Genetic Testing Screening for BRCA1 Mutations in Patients with Triple Negative Breast Cancer and Basal Phenotype.

27 Berliner JL, Fay AM. Risk assessment and genetic counselling for hereditary breast and ovarian cancer: recommendations of the National Society of Genetic Counselors. [Review]. J Genet Counsel 2007; 16: 241-260.

28 Rodriguez-Bigas MA, Boland CR, Hamilton SR et al. A National Cancer Institute workshop on hereditary nonpolyposis colorectal cancer syndrome: meeting highlights and the Bethesda guidelines. J Natl Cancer Instit 1997; 89: 1758-1762.

29 Umar A, Boland CR, Terdiman JP et al. Revised Bethesda guidelines for hereditary nonpolyposis colorectal cancer syndrome (Lynch syndrome) and microsatellite instability. J Natl Cancer Inst 2004; 96: 261-268.

30 Berends MJ, Wu Y, Sijmonds RH et al. Towards new strategies to select young endometrial cancer patients for mismatch repair gene mutation analysis. J Clin Oncol 2003; 21: 4364-4370.

31 Hartge P. Designing early detection programs for ovarian cancer. $J$ Natl Cancer Inst 2009; 102: 3-4.

32 Hampel H, Frankel W, Panescu J et al. Screening for Lynch syndrome (hereditary nonpolyposis colorectal cancer syndrome) among endometrial cancer patients, Cancer Res 2006; 66: 7810-7817.

33 Lim MC, Seo SS, Kang S, Seong MW, Lee BY \& Park SY. Hereditary non-polyposis colorectal cancer/Lynch syndrome in Korean patients with endometrial cancer. Japan J Clin Oncol 2010; 40: 1121-1127.

34 Walsh C, Blum A, Walts A et al. Lynch syndrome among gynecologic oncology patients meeting the Bethesda guidelines for screening. Gynecol Oncol 2010; 116: 516-521.

35 Domchek SM, Eisen A, Calzone K, et al. Application of breast cancer risk prediction models in clinical practice. J Clin Oncol 2003; 21:593-601. 
36 Amir E, Freedman OC, Seruga B, Evans DG. Assessing women at high risk of breast cancer: a review of risk assessment models. $J$ Natl Cancer Inst 2010; 102:680-691.

37 Stratton JF, Pharaoh PDP, Smith SK, Easton CF, Ponder BAJ. A systematic review and meta-analysis of family history and risk of ovarian cancer. Br J Obstet Gynaecol 1998; 105:493-499.

38 Lucenteforte E, Talamini R, Montella M et al. Family history of cancer and the risk of endometrial cancer. Eur J Cancer Prev 2009; 135:35-40.

39 Lee JS, John EM, McGuire V, Felberg A, Ostrow KL \& DiCioccio RA. Breast and ovarian cancer in relatives of cancer patients with and without BRCA mutations. Cancer Epidemiol Biomarkers Prev 2006; 15: 359-363.

40 Gayther SA, Mangion J, Rusell P, Seal S, Barfoot R \& Ponder BA. Variation of risks of breast and ovarian cancer associated with different germline mutations of the BRCA2 gene. Nat Genet 1997; 15: 103-105.

41 Kiely BE, Jenkins MA, McKinley JM, Friedlander ML, Weideman P, et al. Contralateral risk-reducing mastectomy in BRCA1 and BRCA2 mutation carriers and other high-risk women in the Kathleen Cuningham Foundation Consortium for Research into Familial Breast Cancer (kConFab). Breast Cancer Res Treat 2010; 120:725-726.

42 Bosse K, Rhiem K, Wappenschmidt B, Hellmich M, Madeja M \& Ortmann M. Screening for ovarian cancer by transvaginal ultrasound and serum CA125 measurement in women with a familial predisposition: a prospective cohort study. Gynecol Oncol 2006; 103: 1077-1082.

43 Rabban JT, Barnes M, Chen LM, Powell CB, Crawford B, Zaloudek CJ. Ovarian pathology in risk-reducing salpingo-oophorectomies from women with BRCA mutations, emphasizing the differential diagnosis of occult primary and metastatic carcinoma. Am J Surg Pathol 2009; 33:1125-1136.

44 Rebbeck TR, Lynch HT, Neuhausen SL et al. Prophylactic oophorectomy in carriers of BRCA1 and BRCA2 mutations. $N$ Eng J Med 2002; 346: 16161622.

45 Rebbeck TR, Wang Y, Kantoff PW, Krithivas K, Neuhausen SL \& Godwin AK. Modification of BRCA1- and BRCA2-associated breast cancer 
risk by AlB1 genotype and reproductive history. Cancer Res 2011; 61: 54205424.

46 Metcalfe KA, Lynch HT, Ghadirian P, Tung N, Olivotto IA \& Foulkes WD. The risk of ovarian cancer after breast cancer in BRCA1 and BRCA2 carriers. Gynecol Oncol 2005; 96: 222-226.

47 Lécuru F, Huchon C, Metzger U et al. Contribution of ultrasonography to endometrial cancer screening in patients with hereditary nonpolyposis colorectal cancer / Lynch syndrome. Intl J Gynecol Cancer 2010; 20: 583-587.

48 Evans DG, Clayton R, Donnai P, Shenton A, Lalloo F. Risk-reducing surgery for ovarian cancer: outcomes in 300 surgeries suggest a low peritoneal primary risk. Eur J Hum Genet 2009; 17:1381-1385.

49 Tobacman JKI, Greene MH, Tucker MA, Costa J, Kase R \& Fraumeni JF. Intra-abdominal carcinomatosis after prophylactic oophorectomy in ovarian cancer prone families. Lancet 1982; 2: 795-797.

50 Hirst JE, Gard GB, McIllroy K, Nevell D, Field M. High rates of occult fallopian tube cancer diagnosed at prophylactic bilateral salpingooophorectomy. Int J Gyn Cancer 2009; 19(5):826-829.

51 Thompson D, Easton DF, and the Breast Cancer Linkage Consortium. Cancer Incidence in BRCA1 Mutation Carriers. J Natl Inst 2002; 94: 13581365 .

52 Hebert-Blouin M, Koufogianis V, Gillett P, Foulkes WD. Fallopian tube cancer in a BRCA1 mutation carrier: Rapid development and failure of screening. Am J Obstet Gynecol; 2002; 186: 53-54.

53 Rose PG, Shrigley R, Wiesnert GL. Germline BRCA2 Mutation in a Patient with Fallopian Tube Carcinoma: A Case Report. Gynaecol Oncol 2000; 77: 319-320.

54 Zweemer RP, Van Diest PJ, Verheijen RH, Ryan A, Gille JP \& Sijmons RH. Molecular evidence linking primary cancer of the fallopian tube to BRCA1 mutations. Gynecol Oncol 2000; 76: 45-50.

55 Slomovitz BM, Burke T, Eifel P, Ramondetta LM, Silva E \& Jhingran A. Uterine papillary serous carcinoma (UPSC): a single institution review of 129 cases. Gynecol Oncol 2003; 91: 463-469. 
56 Rhiem K, Fischer C, Bosse K, Wappenschmidt B, Schmutzler RK. Increased risk of cervical cancer in high-risk families with and without mutations in the BRCA1 and BRCA2 genes. J Clin Oncol 2007; 25: 5588.

57 Rubin SC, Blackwood MA, Bandera C et al. BRCA1, BRCA2 and hereditary non polyposis colorectal cancer gene mutations in an unselected ovarian cancer population: relationship with family history and implications for genetic testing. Am J Obstet Gynecol 1998; 178: 670-677.

58 Meyer LA, Westin SN, Lu KH, Milam MR. Genetic polymorphisms and endometrial cancer risk. Expert Anticancer Ther 2008; 8: 1159-1167.

59 Bonadona V, Bonaiti B, Olschwang S et al. Cancer risks associated with germline mutations in MLH1, MSH2 and MSH6 genes in Lynch syndrome. JAMA 2011; 305: 2304 DOI

60 Burke W, Peterson G, Lynch P et al. Recommendations for follow-up care of individuals with an inherited predisposition to cancer. I Hereditary nopolyposis colon cancer. Cancer Genetics Studies Consortium. JAMA 1997; 277: 915-919.

61 Lu KH, Schorge JO, Rodabaugh KJ et al. Prospective determination of prevalence of Lynch syndrome in young women with endometrial cancer. J Clin Oncol 2007; 25:5158-5164.

62 Watson P, Butzow R, Lynch HT, Mecklin JP, Jarvinen HJ. The clinical features of ovarian cancer in hereditary nn-polyposis colon cancer. Gynecol Oncol 2001; 82: 223-228.

63 Heald B, Mester J, Rybicki L. Frequent gastrointestinal polyps and colorectal adenocarcinoma in a prospective series of PTEN mutation carriers. Gastroenterology 2010;139: 1927-1933.

64 Eng C. Will the real Cowden syndrome please stand up: revised diagnositic criteria. J Med Genet 2000; 37: 828-830.

65 Partridge E, Kreimer AR, Greenlee RT et al. Results from four rounds of ovarian cancer screening in a randomized trial. Obstet Gynecol 2009; 113: 775782.

66 Menon U, Gentry-Maharaj A, Hallett R et al. Sensitivity and specificity of multimodal and ultrasound screening for ovarian cancer, and stage 
distribution of detected cancers: results of the prevalence screen of the UK Collaborative Trial of Ovarian Cancer Screening (UKCTOCS) Lancet Oncol 2009; 10:327-340.

67 Lux M, Ackermann S, Nestle-Kramling C, Goeke TO, Niederacher d \& Bodden-Heidrich R. Use of intensified early cancer detection in high-risk patients with familial breast and ovarian cancer. Europ J Cancer Prev 2005; 14: $399-411$.

68 Anderson GL, McIntosh M, Wu L et al. Assessing lead time of selected ovarian cancer biomarkers: a nested case-control study. J Natl Cancer Inst 2009; 102: 26-37.

69 Cohen LS, Escobar PF, Scgharm C, Glimco B, Fishman DA. Threedimensional power Doppler ultrasound improves the diagnostic accuracy for ovarian cancer prediction. Gynaecol Oncol 2001; 82: 40-48.

70 Eitan R, Michaelson-Cohen R, Levavi H \& Beller U. The counselling and management of young healthy BRCA mutation carriers. Int J Gynecol Cancer 2009; 19: 1156-1159.

71 Gulden C, Olopade OI. Risk assessment and genetic testing for ovarian cancer. Am J Roentgenol 2010; 194:309-310.

72 Greene MH, Piedmonte M, Alberts D, Gail M, Hensley M \& Miner Z. A prospective study of risk-reducing salpingo-oophorectomy and longitudinal CA125 screening among women at increased genetic risk of ovarian cancer: design and baseline characteristics: a Gynecologic Oncology Group study. Cancer Epidemiol Biomark Prevent 2008; 17: 594-604.

73 Persadie RJ. Ultrasonographic assessment of endometrial thickness: a review. J Obstet Gynecol Can 2002; 24:131-136.

74 Duffy S, Jackson TL, Lansdown M, et al. ATAC Tralists' Group. The ATAC adjuvant breat cancrer trial: baseline endometrial sub-protocol data on the effectiveness of transvaginal ultrasonography and diagnostic hysteroscopy. Hum Reprod 2005; 20: 294-301.

75 Fung MF, Bryson P, Johnston M, Chambers A. Screening postmenopausal women for ovarian cancer: a systematic review. J Obstet Gynaecol Can 2004; 26: 717-728. 
76 Kauff ND, Satagopan JM, Robson ME et al. Risk-reducing salpingooophorectomy in women with a BRCA1 or BRCA2 mutation. $N$ Eng $J$ Med 2002; 346: 1609-1615.

$77 \mathrm{Lu} \mathrm{KH}$, Kauff ND. Does a BRCA mutation plus tamoxifen equal hysterectomy? Gynecol Oncol 2006; 104: 3-4.

78 Fischer B, Costantino JP, Wickerham DL et al. Tamoxifen for prevention of breast cancer: report of the national surgical adjuvant breast and bowel project P-1 study. J Natl Cancer Instit 1998; 90: 1371-1379.

79 Howard AF, Balneaves LG \& Botorff JL. Women's decision making about risk-reducing strategies in the context of hereditary breast and ovarian cancer: a systematic review. J Genet Counsel 2009; 18 :578-597.

80 Gabriel CA, Tigges-Cardwell J, Stopfer J, Erlichman J, Nathanson K, Domchek SM. Use of total abdominal hysterectomy and hormone replacement therapy in BRCA1 and BRCA2 mutation carriers undergoing risk-reducing salpingo-oophorectomy. Fam Cancer 2009; 8:23-28.

81 Lancaster JM, Powell CB, Kauff ND et al. Society of Gynecologic Oncologists Educational Committee statement on risk assessment for inherited gynecologic cancer predispositions. Gynecol Oncol 2007; 107: 159-162.

82 Metcalfe KA, Birenbaum-Carmeli D, Lubinski J, Gronwald J, Lynch H, et al. International variation in rates of uptake of preventive options in BRCA1 and BRCA2 mutation carriers. Int J Cancer. 2008; 122:2017-2022.

83 Early Breast Cancer Trialists "Collaborative Group". Ovarian ablation in early breast cancer: overview of the randomised trials. Lancet 1996; 348: 11891196.

84 Lux MP, Ackermann S, Bani MR, Nestle-Kraming C, Goecke TO \& Niederacher D. Age of uptake of early cancer detection facilities by low-risk and high-risk patients with familial breast and ovarian cancer. Europ J Cancer Prevent 2005; 14: 503-511.

85 Goshen $\mathrm{R}$, Chu W, Elit $\mathrm{L}$ et al. Is uterine serous papillary adenocarcinoms a manifestation of the hereditary breast-ovarian cancer syndrome? Gynecol Oncol 2000; 79: 477-481. 
86 Pijpe A, Manders P, Brohet RM, Collee JM, Verhoef S, et al. Physical activity and the risk of breast cancer in BRCA1/2 mutation carriers. Breast Cancer Res Treat 2010; 120:235-244.

87 Klitzman R, Chung W. The process of deciding about prophylactic surgery for breast and ovarian cancer: Patient questions, uncertainties, and communication. Am J Med Genet 2010; 152:52-66.

88 Meijers-Heijboer H, Brekelmans CTM, Menke-Pluymers M, Seymaeve C, Baalbergen A \& Burger C. Use of Genetic Testing and Prophylactic Mestectomy and Oophorectomy in Women With Breast of ovarian Cancer From Families With a BRCA1 or BRCA2 Mutation. J Clin Oncol 2003; 21: 16751681.

89 Morgan D, Sylvester H, Lucas FL, Miesfeldt S. Cancer prevention and screening practices among women at risk for hereditary breast and ovarian cancer after genetic counseling in the community setting. Fam Cancer 2009; 8:277-287.

90 Rebbeck TR, Friebe T, Lynch HT et al. Bilateral prophylactic mastectomy reduces breast cancer risk in BRCA1 and BRCA2 mutation carriers: the PROSE study group. J Clin Oncol 2004; 22: 1055-1062.

91 Price MA, Butow PN, Charles $\mathrm{M}$ et al. Predictors of breast cancer screening behaviour in women with a strong family history of the disease. Breast Cancer Res Treat 2010; 124: 509-519.

92 Kelly KM, Senter L, Leventhal H, Ozakinci G, Porter K. Subjective and objective risk of ovarian cancer in Ashkehazi Jewish women testing for BRC1/2 mutations. Patient Educat Counsel 2008; 70: 135-142.

93 Antoniou AC, Hardy R, Walker L et al. Predicting the likelihood of carrying a BRCA1 or BRCA 2 mutation: validation of BOADICEA, BRCAPRO, IBIS, Myriad and the Manchester scoring systems using data from UK genetics clinics. J Med Genet 2008; 45: 425-431. 